\title{
WALL-E in Real Life
}

\author{
C. C. Chancey, Editor \\ American Journal of Undergraduate Research \\ University of Northern lowa \\ Cedar Falls, lowa 50614-0150 USA
}

The phrase "real life" in the title might seem misplaced since WALL-E is a computeranimated robot made famous in a recent film. The popularity of WALL-E, EVE and their ilk is certainly testifies to their roles in our imaginations, but what about real-world WALL-E's and EVE's? Robots do appear in television commercials-often constructing cars, however these robots don't appear to have any capacity for social interaction.

The widespread success of the FIRST Lego League and FIRST Tech Challenge programs in primary and secondary schools has helped publicize robots among children-and parents. But high-end robotics is still the preserve of research laboratories. Robotics and Artificial Intelligence $(\mathrm{Al})$ research programs at universities and corporate labs have given us robotic fish and other animals that appear to mimic real behaviors.

What about humanoid robots that can talk with us intelligently? Such robots would be the real versions of those that appear in film. A search of "humanoid robots" on Youtube.com will answer the question. Video clips show some quite

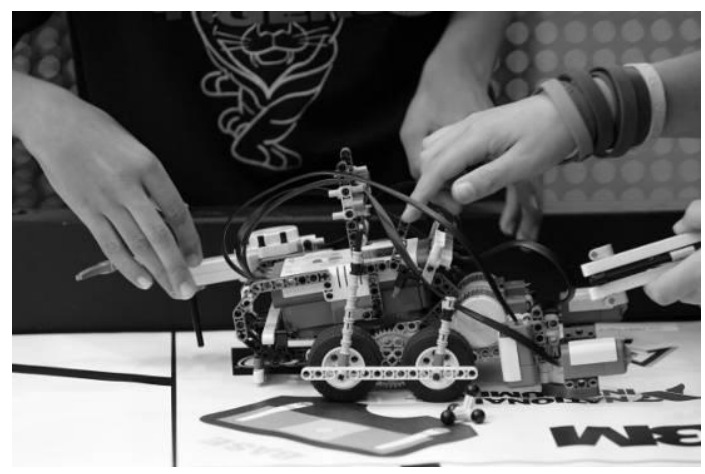

FIRST Lego league robot at Driscoll Upper School in Massachusetts.

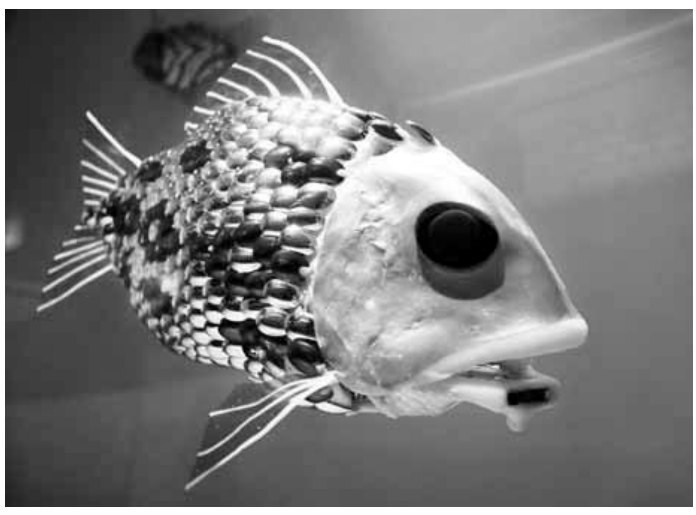

A robotic fish at the University of Essex, UK.

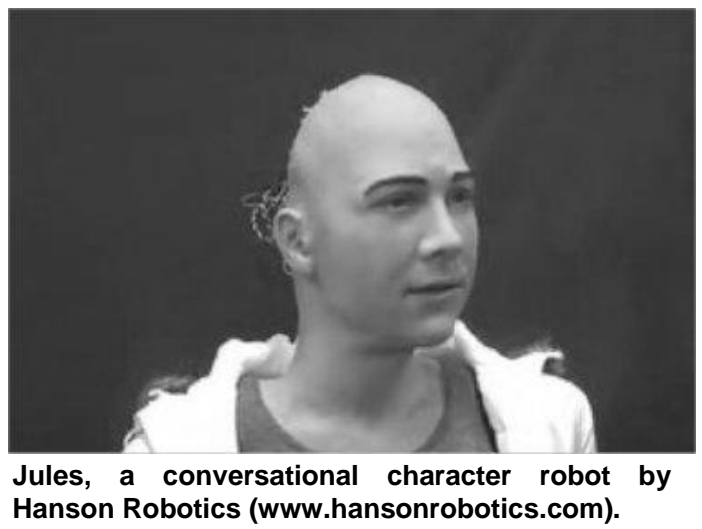

human-like behaviors. Jules is one of these: a conversational character robot created by Hanson Robotics. He makes simple but intelligent conversation and readily expresses emotional attachments. Jules is remarkable for the life-like expressions he can show: smiling, squinting his eyes, wrinkling his forehead in apparent thought. Jules is clearly an artistic and technicallyadept creation. (Watch some of the Youtube videos.)

Can undergraduate robotics programs be far away, buttressed as they are by FIRST and Hanson? 